\title{
Capsule Commentary on Rana et al., Diabetes and Prior Coronary Heart Disease Are Not Necessarily Risk Equivalent for Future Coronary Heart Disease Events
}

\author{
Tiffany M. Powell-Wiley, MD, MPH \\ Cardiovascular and Pulmonary Branch, Division of Intramural Research, National Heart, Lung, and Blood Institute, National Institutes of Health, \\ Bethesda, MD, USA.
}

J Gen Intern Med 31(4):413

DOI: $10.1007 / \mathrm{s} 11606-016-3605-6$

๑) Society of General Internal Medicine 2016

$\mathrm{T}$ he prevalence of diabetes mellitus (DM) has risen dramatically over the past decades as obesity rates have increased in the United States. Recent estimates suggest that approximately $9 \%$ of the U.S. population, or over 29 million Americans, have DM, with the great majority having Type 2 DM. ${ }^{1}$ While cardiovascular disease is known to be the leading cause of death among those with diabetes, ${ }^{2}$ there has been controversy as to whether prevalent diabetes portends the same risk for future cardiovascular events as prevalent coronary heart disease (CHD). Delineating diabetes as a CHD equivalent or a CHD risk factor is critical to improving the accuracy of cardiovascular risk prediction and in developing tailored risk reduction strategies.

Rana and colleagues analyzed electronic health record data from the Kaiser Permanente Northern California health care system, which includes over 1.5 million members. ${ }^{3}$ This study demonstrated that the risk of a CHD event over a 10 -year follow-up period was significantly lower for those with diabetes alone as compared to those with prior CHD; these findings appear to refute previous data showing that prevalent diabetes is a CHD equivalent. ${ }^{4}$ Most interestingly, those with diabetes for the longest duration, or for ten or more years in the cohort, had a similar risk of CHD events as those with CHD alone.

The findings are robust, given that much of the prior data examining diabetes as a CHD risk equivalent comes from metaanalyses with inherent methodologic limitations, and this study was done in a large, ethnically and racially diverse population from a real-world setting. Additionally, sex-stratified analyses of CHD event rates in this population help to identify whether CHD risk based on prevalent diabetes differs between men and women. One area for future work with this study cohort would be to evaluate

This comment refers to the article available at: http://dx.doi.org/10.1007/ s11606-015-3556-3.

Published online February 12, 2016 differences in CHD event rates across racial and ethnic groups among those with diabetes and/or CHD as compared to those without either disease. Overall, these findings support the use of outcomes data from diverse patient populations for creating and refining cardiovascular risk prediction models, as was used in the creation of the 2013 ACC/AHA cardiovascular risk estimator. ${ }^{5}$

The author has no conflict with any of the material in this manuscript. Funding support for the author is provided by the Division of Intramural Research of the National Heart, Lung, and Blood Institute (NHLBI) at the National Institutes of Health (NIH). The views expressed in this manuscript are those of the author and do not necessarily represent the views of the National Heart, Lung, and Blood Institute; the National Institutes of Health; or the U.S. Department of Health and Human Services.

Corresponding Author: Tiffany M. Powell-Wiley, MD, MPH; Cardiovascular and Pulmonary Branch, Division of Intramural Research, National Heart, Lung, and Blood InstituteNational Institutes of Health, Bethesda, MD 20892, USA (e-mail: Tiffany.powell@nih.gov).

\section{REFERENCES}

1. Regensteiner JG, Golden S, Huebschmann AG, Barrett-Connor E, Chang AY, Chyun D, et al. Sex differences in the cardiovascular consequences of diabetes mellitus: a scientific statement from the American Heart Association. Circulation. 2015;132(25):2424-47. doi:10.1161/CIR. 0000000000000343.

2. Fox CS, Golden SH, Anderson C, Bray GA, Burke LE, de Boer IH, et al. Update on prevention of cardiovascular disease in adults with type 2 diabetes mellitus in light of recent evidence: a scientific statement from the American Heart Association and the American Diabetes Association. Circulation. 2015;132(8):691-718. doi:10.1161/CIR.0000000000000230.

3. Rana JS, Liu JY, Moffet HH, Jaffe M, Karter AJ. Diabetes and prior coronary heart disease are not necessarily risk equivalent for future coronary heart disease events. JGIM. 2016. doi:10.1007/s11606-0153556-3.

4. Haffner SM, Lehto S, Ronnemaa T, Pyorala K, Laakso M. Mortality from coronary heart disease in subjects with type 2 diabetes and in nondiabetic subjects with and without prior myocardial infarction. N Engl JMed. 1998;339:229-34.

5. Goff DC Jr, Lloyd-Jones DM, Bennett G, Coady S, D'Agostino RB Sr, Gibbons R, Greenland P, Lackland DT, Levy D, O'Donnell CJ, Robinson JG, Schwartz JS, Shero ST, Smith SC Jr, Sorlie P, Stone NJ, Wilson PW, American College of Cardiology/American Heart Association Task Force on Practice Guidelines. 2013 ACC/AHA guideline on the assessment of cardiovascular risk: a report of the American College of Cardiology/ American Heart Association Task Force on Practice Guidelines. J Am Coll Cardiol. 2014;63(25 Pt B):2935-59. 